\title{
Perforated Acute Abdomen in a Immunossuppressed Patient due to Strongyloides stercoralis Hyperinfection Syndrome
}

\section{Luis Felipe Gomes de Souza' 1 , Livia Gabriélle Silva Carvalho}

\begin{abstract}
${ }^{1}$ Resident in general surgery of Faculdade de Medicina de São José do Rio Preto and Hospital de Base, São José do Rio Preto, São Paulo, Brazil
Abstract: Strongyloidiasis is caused by Strongyloides stercoralis, an endemic parasite in tropical regions of the world. The symptoms are mostly indolent and related to the gastrointestinal tract, however in immunosuppressed individuals, the disease can escalate to critical conditions due to a hyperinfection. This study aims to report a case of an elderly patient in oncologic treatment for a laryngeal cancer, who presented a perforated acute abdomen that required emergency laparotomy with an enterectomy, whose anatomopathological analysis revealed an important Strongyloides infection.
\end{abstract}

Keywords: Strongyloidiasis, Hyperinfection Syndrome, Intestinal Perforation, Immunosuppression

\section{Introduction:}

Strongyloidiasis is a helminthiasis caused by Strongyloides stercoralis, a nematode endemic in tropical countries such as Brazil. It usually affects the gastrointestinal tract and occasionally the lungs due to its life cycle. $(1,6,7)$ Although most cases manifest themselves asymptomatically or with mild symptoms, immunosuppressed patients can develop disseminated disease and a severe hyperinfection. These infirms often present severe and refractory sepsis with unfavorable outcomes. (3,5) The diagnosis of strongyloidiasis is based on the microscopic identification of larvae (rhabditiform and occasionally filariform) in the stool or duodenal fluid. However, their presence in histopathological analyses has increased in recent years due to the large amount of hyperinfection cases in immunocompromised patients. The aim of this report tis to present the case of one of those patients, who was admitted to our service with perforated acute abdomen due to a Strongyloides hyperinfection syndrome.

\section{Case report:}

The patient was a 71-year-old man in oncological care due to a poorly differentiated carcinoma of larynx, ongoing chemotherapy and radiation therapy due to residual disease. The cancer diagnosis had been made four months before this report. He was admitted to the emergency room with complaints of abdominal pain, nausea and emesis initiated 8 hours before the admission. Physical examination revealed him to be very weak, slim, hypotensive, tachycardic and with peritonitis. The blood count presented leukocytosis $\left(14360 / \mathrm{mm}^{3}\right)$ with left shift, but without eosinophilia. A CT scan showed a moderate amount of free fluid in the abdominal cavity, with signs of possible pneumoperitoneum (Figure 1). Exploratory laparotomy was indicated, in which moderate amount of serous liquid was evidenced in the cavity, as well as a perforated diverticulum at one meter from the angle of Treitz. As a result, a segmental enterectomy with primary anastomosis was performed (Figure 2).

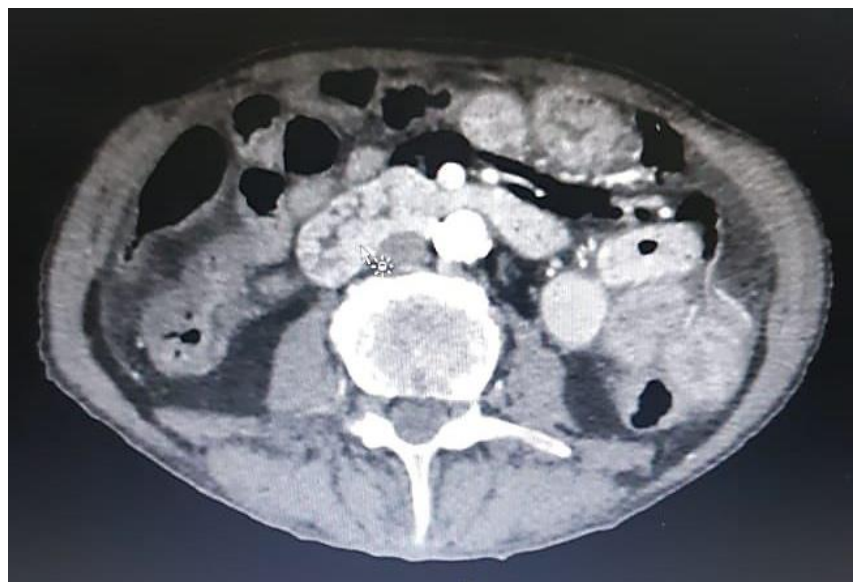

Figure 1. Abdominal CT scan (axial view) evidencing hyperuptake zones in small intestine bowels, suggesting peritonitis, also associated with signs of pneumoperitoneum dissecting the mesenteric root.

Abdominal CT scan (axial view) evidencing hyper-uptake zones in thin intestinal loops, suggesting peritonitis process. Associated with signs of pneumoperitoneum dissecting the root of the mesenteric. 


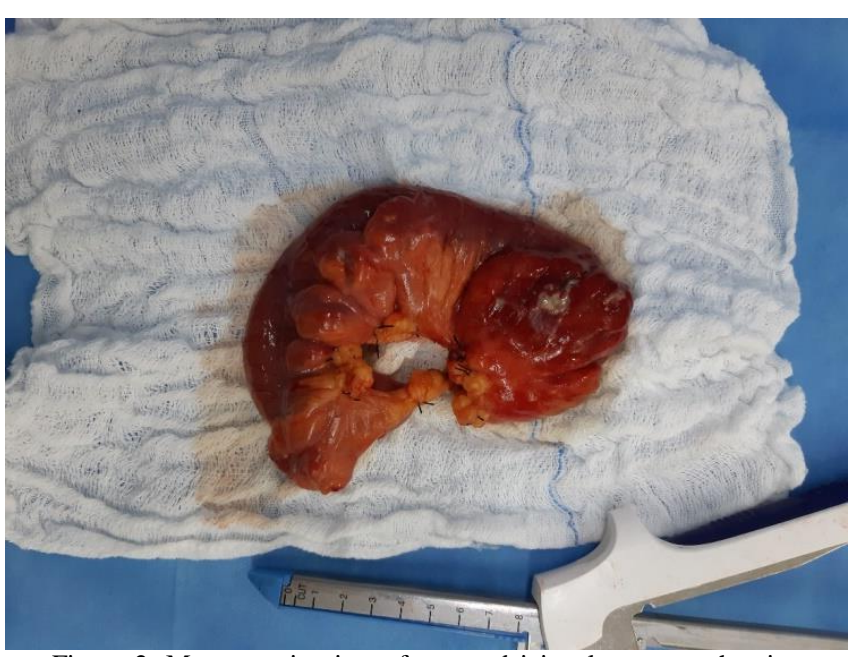

Figure 2. Macroscopic view of resected jejunal segment showing perforated diverticulum.

After the procedure, he developed an apparent hemodynamic improvement, but worsening of the respiratory condition. On the sixth post-operative day, the pathological result of the surgical specimen showed an important infestation by Strongyloides stercoralis, and therefore drug treatment with Ivermectin was started considering a hyperinfection condition triggered by the parasite. Three days later, the patient again presented significant clinical worsening and was re-approached due to possible anastomotic dehiscence, which was confirmed and repaired during surgery. Despite all the measures, he evolved with septic shock refractory to antimicrobial therapies, multiple organ failure, followed by death a few days later.

\section{Discussion:}

Strongyloidiasis still represents a cause of helminthiasis with the potential of catastrophic outcomes, mainly in tropical regions, where there are higher rates of poor sanitation and hygiene conditions $(3,6,7)$. Although most cases remain asymptomatic for a long time or with mild gastrointestinal symptoms, severe infections at risk of death can occur and should always be included in the differential diagnosis of acute abdomen in endemic areas, as severe gastrointestinal symptoms, due to increased parasitic load, occur in hyperinfection syndrome $(9,10)$. The pathogenesis occurs when the reinfection cycle begins and the parasitic intraluminal load increases. The filariform larvae of $S$. stercoralis invade the intestinal walls and can spread through the lymphatic and hematogenous pathways to distant organs, such as liver, pancreas, lungs and central nervous system, triggering an intense multisystemic inflammatory response $(5,11,12)$. This hyperinfection is usually accompanied by Gramnegative septicemia somehow facilitated by infectious filariform larvae through the intestinal mucosa, leading to high mortality rates $(3,6)$. Severe cases of autoinfection are invariably associated with a clear cause of immunosuppression, namely: corticosteroid therapy, chemotherapy agents, chronic immunodeficiency, intestinal motility disorders, chronic renal failure, diabetes mellitus, malnutrition, alcoholism, malignant diseases, post-transplant and HTLV-1 infection (1, 5, 10, 12). Clinically, these severe forms of infection can be preceded by watery diarrhea, abdominal cramps, and often indolent weight loss. Hematemesis, partial obstruction of the small intestine and paralytic ileus have also been reported, but intestinal perforation is rarely described $(3,7)$. In 2015, Figueira et al. (3) described the case of perforated abdomen with ileal loop necrosis in a patient with intestinal motility disorder who, despite surgical treatment, died of septicemia. In 2012, Romero-Cabello et al. (11) also reported a similar case of hyperinfection by postmortem diagnosed strongyloidiasis in an HIV-positive patient, after analysis of a resected surgical specimen. In the present report, the pathological finding was suppurative perforated diverticulitis with severe infestation by Strongyloides stercoralis.

The diagnosis of severe forms of $S$. stercoralis infection is challenging and therefore a high degree of clinical suspicion is necessary $(3,6,10)$. Imaging studies are not specific, and eosinophilia is infrequent in states of immune depression $(2,3,4)$. The diagnosis can be confirmed by low-invasive methods. Therefore, high suspicion in high-risk patients should be followed by obtaining biological materials (gastric or duodenal aspirate and tracheal fluid) or biopsies of suspicious lesions so that treatment can be started early (8). However, what is commonly observed are late incidental diagnoses by surgical specimens in patients with severe conditions $(3,5)$. In the present case, the diagnosis of strongyloidiasis hyperinfection was made only after surgery by pathological examination of the surgical specimen. Although specific antiparasitic treatment with ivermectin was installed, the advanced damage and complications of intestinal perforation and secondary bacterial sepsis greatly hindered the patient's response to treatment, leading to his death. Thus, this report highlights the importance of preoperative evaluation of immunosuppressed conditions, even in emergency situations, as they can lead to potentially fatal complications $(2,8,10)$.

\section{Conclusion:}

The possibility of Strongyloides stercoralis hyperinfection should be considered in the differential diagnosis of acute abdomen in immunosuppressed patients, especially in endemic regions. Appropriate and timely therapy prior to the development of significant abdominal complications, such as perforation and peritonitis, may reduce the high mortality rates observed. 


\section{References:}

1- Bueno, M. S.; Oliveira, 1. B. De.; Machado, e. R.; Souza, M. S. De.; Axhcar, 1. C. G. Estrongiloidiase Disseminada em Pacientes com Doenças Autoimunes: Uma Revisão Sistemática da Literatura. Revista de Iniciação Científica e Extensão, [S. 1.], v. 2, n. Esp.1, p. 44, 2019. Available on: https://revistasfacesa.senaaires.com.br/index.php/iniciacaocientifica/article/view/220. Accessed: 25 May 2021

2- Costa Castilho, Josiane et al. Estrongiloidíase Disseminada No Imunossuprimido: Relato De Caso. Revista de Ciências da Saúde da Amazônia, [S.1.], n. 1, p. 64-69, set. 2018. ISSN 2447-486X.

3- Figueira CF, Gaspar MT, Cos LD, Ussami EY, Otoch JP, Felipe-Silva A. Strongyloides stercoralis hyperinfection associated with impaired intestinal motility disorder. Autops Case Rep. 2015;5(2):27-34. Published 2015 Jun 30. doi:10.4322/acr.2015.005.

4- Frota, José Henrique et al. Intestinal strongyloidiasis: radiological findings that support the diagnosis. Radiologia Brasileira [online]. 2017, v. 50, n. 2 [Accessed 25 May 2021], pp. 137-138. Available from: <https://doi.org/10.1590/0100-3984.2015.0175>. ISSN 16787099. https://doi.org/10.1590/0100-3984.2015.0175.

5- Incani, Renzo Nino, Hernández, Marcos and González, María Elena. Hyperinfection by Strongyloides stercoralis probably associated with Rituximab in a patient with mantle cell lymphoma and hyper eosinophilia. Revista do Instituto de Medicina Tropical de São Paulo [online]. 2010, v. 52, n. 4 [Accessed 25 May 2021], pp. 221-224. Available from: <https://doi.org/10.1590/S0036-46652010000400011>. Epub 25 Aug $2010 . \quad$ ISSN 1678-9946. https://doi.org/10.1590/S0036-46652010000400011.

6- Karanam L, SK, Basavraj, GK \& Papireddy, CKR Strongyloides stercoralis Hyper Infection Syndrome. Indian

Surg (2020). https://doi.org/10.1007/s12262-020-02292-x.

7- Kushima, A; Takahashi, M; Takahashi, K; Hachisuka, H; Nunomura, M. A case of perforation of the intestine caused by Strongyloides stercoralis. Journal of Japan Surgical Association, v. $\quad 71, \mathrm{n} . \quad 11, \mathrm{p} . \quad 2855-2859,2010$ https://doi.org/10.3919/jjsa.71.2855

8- Luna, Olívia Barberi et al. Estrongiloidíase disseminada: diagnóstico e tratamento. Revista Brasileira de Terapia Intensiva [online]. 2007, v. 19, n. 4 [Access: 25 May 2021] pp. 463-468. Disponível em: <https://doi.org/10.1590/S0103507X2007000400010>. Epub 22 Jan 2008. ISSN 1982-4335. https://doi.org/10.1590/S0103-507X2007000400010.

9- Ozturk, G., Aydinli, B., Celebi, F. and Gursan, N. (2011). Ga stric perforation caused by Strongyloides stercoralis: a case report. Turkish Journal of Trauma and Emergency Surgery 17, 90-92. doi: 10.5505/tjtes.2011.51196.

10- Rodrigues, Maria Aparecida Marchesan et al. Invasive enteritis by Strongyloides stercoralis presenting as acute abdominal distress under corticosteroid therapy. Revista do Hospital das Clínicas [online]. 2001, v. 56, n. 4 [Accessed 25 May 2021], pp. 103-106. Available from: <https://doi.org/10.1590/S0041-87812001000400002>. Epub 13 Nov 2001. ISSN 1678-9903. https://doi.org/10.1590/S0041-87812001000400002.

11- Romero-Cabello R, Villagroy Gómez J, Hernández González M, Romero Feregrino R. Hyperinfection with Strongyloides stercoralis. BMJ Case Rep. 2012; 2012: bcr2012006819. Published 2012 Nov 30. Doi: 10.1136/bcr-2012-006819

12- Santana, ATT; Loureiro, MB. Síndrome de hiperinfecção e/ou disseminação por Strongyloides stercoralis em pacientes imunodeprimidos. Revista Brasileira de Análises Clínicas, 2016. 